\section{Nuclear And Peripheral Relations In The Category Of Noun In Uzbek Language}

\author{
Normominov Sherzod Toychievich, \\ Samarkand State University, Uzbekistan
}

\author{
G open ACCess \\ The American Journal of \\ Social Science And \\ Education Innovations \\ JULY 2020 \\ Page No.: 97-103 \\ Volume-II Issue-VII \\ PUBLISHED: 30 JULY 2020 \\ www.usajournalshub.com/inde \\ x.php/tajssei \\ Copyright: Original content \\ from this work may be used \\ under the terms of the \\ Creative Commons Attribution \\ 4.0 licence.
}

\title{
Abstract
}

In world linguistics, a lot of research has been done on the theory of word groups, the role of word groups in the language system and the essence of functional-semantic processes that occur in the paradigm of word groups. From this point of view, this article presents the nuclear (central) and peripheral (peripheral) parts of the noun category in the paradigm of Uzbek word groups, their formation and development; Attempts have been made to examine the functional-semantic features of modern research methods and to expand the perspective of scientific research carried out in this area so far, to open new directions for future research.

Keywords: word categories, paradigm, core, periphery, definite noun, cognate noun, abstract noun, singular, plural.

\section{Introduction}

The study of the nuclear and peripheral parts of the structural-semantic field of the paradigm of word groups and individual word groups in world linguistics, the identification 
of linguistic and speech features of the development and communicative function of language, spiritual and formal changes in language units it is noted that the mechanism helps to determine the leading motives. One of the important tasks is to study the issues of nuclear peripherals in the Uzbek language. In the Uzbek language, the lexical unit that answers the question of who, what, where is called a being, thing, place, event, process is called a noun. "To call a being or a part of it as an object" is the general grammatical meaning of the noun phrase. In this case, the concept of the subject has a grammatical meaning, not a logical one. An object that is logically inanimate and directly affects the member of the senses is called an object. In grammar, it is understood in a broad sense, it is considered to have the essence of "existence" [2. 208]. As is clear from this definition, in the language system of nouns, it means objectivity, regardless of whether the object it represents is logically material or ideal (thought). Therefore, based on the meaning of the word and other functional-semantic and functional-syntactic features, it is necessary to determine which types of nouns are located in the nucleus, which species are located in the periphery.

\section{The Main Findings And Results}

Words in the noun category have the ability to perform two different semiological functions; they not only name things but also describe them. The fact that these functions are assigned to a single unit leads to the formation of specific predicative and attributive compounds. When it comes to the semantic features of nouns, first of all, it is necessary to distinguish their place in the series of nominative units and denotative meanings that are activated by their participation in speech structures. In the first case, the denotation is a generalized notion of the object in reality as an object of naming, and in the second, the denotation can be associated with the object in the speech process, that is, with its referent [1. 75].

Also, in terms of the general lexical and grammatical meaning of the noun, it is necessary to dwell on the role of definite and abstract nouns, related and famous noun in the nuclear-peripheral relationship. As defined in the Grammar of the Uzbek Language, concrete noun mean a specific person, a thing. Since concrete nouns denote things that 
can be seen and counted directly, the number takes an adjective represented by a number, and is also used in the singular and plural forms: daftar (notebook)- ikkita (two), daftar (notebook) - daftarlar (notebooks), bola (child) - o'nta (ten), bola (child)- bolalar (children), maktab (school) - uchta (three), maktab (school)- maktablar (schools), qishloq (village) - beshta (five), qishloq (village) - qishloqlar (villages). Abstract nouns, on the other hand, express abstract concepts, character, feature, action, and state as things. These noun do not come in the plural: mundarija- content, sevgi-love, kulgi-lough, go'zallik- beauty, qahramonlik- heroism, vatanparvarlik- patriotism, aql- wisdom, sharafhonor, ovchilik - hunting. Abstract nouns are used in the plural only in some cases. At this point, their abstract meaning is somewhat concretized: zo'r muvaffaqiyatlar - excellent success, katta qiyinchiliklar - great difficulties, shahrimiz yangiliklari - news of our city, bayram shodliklari - holiday joys, bolalik sho'xliklar - childhood joys.

Some of the abstract nouns are made up of primitive words: qalb - heart, shayton - the devil, vijdon - conscience, ko'ngil - heart, niyat - intention, mehnat - labor, ofat disaster. Many abstract nouns are artificial. Abstract noun are made up of adjectives and verbs, as well as the noun themselves. This, in turn, partially preserves the semantic connection in artificial noun with the categories on which they are based, which in turn leads to its departure from the basic (nominative) feature inherent in noun.

The primary and secondary function of noun also has a certain effect on their location in the nucleus and periphery. The noun has the form of a consonant it has taken, and serves as a focus, a complement, a nominative, an explanatory, a motivation, as well as a consonantal form of the case. These are the primary tasks for the noun. The secondary function of noun is as follows: that is, if a noun is adjective; it enters an attributive format and becomes an adjective. The noun also comes in the function of cutting. To do this, a suffix is added after a certain form of agreement. Apparently, the cut is formed not by a consonant, but by a preposition, in which the consonant is syntactically neutralized. Another syntactic nature of the noun lexeme is that it takes an adjective. The word lexeme is also mentioned as one of the distinguishing features of the word from other categories, but it is a minor sign and applies only to artificial noun [3. 124]. Noun that come in the primary function are known to be located in the nucleus, while noun in 
the secondary function are known to be located in the periphery because they are moving away from the noun's typical syntactic function.

It can be said that the attitude of noun to the nuclear periphery also changes in terms of naming individual objects or objects of the same sex. It is well known that a nickname is a secondary name that serves to distinguish one of the same objects or events. For example, a child is the common and primary name of an object (person) of the same type. Anwar is a secondary name that serves to distinguish one of the same subjects (person) and is placed after the term child.

Due to this, the scope of structural features and grammatical possibilities of famous noun seems to be relatively narrow. They also have a low level of activation of grammatical categories.

The status of cognate noun denoting the common name of objects of the same sex is distinct due to the breadth of their lexical-semantic features. Related noun are the main part of the word that belongs to the category of noun: [tog' - mountain], [qishloqvillage], [mashina-car], [sevgi-love], [muhabbat- love]. In the cognate noun, the object and the sign feature are present in a rounded form. Because everything is a set of characters. Therefore, it is natural for related noun to be located in the nucleus, and for famous noun to be located in the periphery.

Among related noun, individual noun are content and functionally opposed to all other noun, so they occupy a place in the nucleus with their own class as a large subdivision of related noun. In particular, individual noun form a separate and large group among related noun. Noun named in terms of a person's profession, activity, constitute the largest, main group of personal noun. This is legal. Because man (man), unlike other living beings, has the ability to think, speak, work. In short, man is a person who works mentally and physically. The main part of a person's name refers to a person according to these characteristics, in connection with his activity. That is why the main (largest) part of a person's noun is such noun. Person noun makers also form words that name a person (person) with the mentioned signs (characteristics): musician, orientalist, grain grower, etc. [4. 61].

It is also important to examine the relationship between another type of noun in 
terms of meaning and functional characteristics - aggregate and individual noun in terms of nuclear-peripheral relationship. It is well known those aggregating nouns are related noun that represent the sum of things of the same sex in a whole case. These nouns do not refer to individual objects in the singular form, but to many objects grouped into one whole: such as people, flock, and fruit. Individual noun, on the other hand, are semantically opposite to aggregating noun and refer to separate objects that are part of a herd. In the singular and plural forms of this noun, things are imagined singularly: kishikishilar - person-people, odam-odamlar- person-people, askar-askarlar - soldier- soldiers, dehqon-dehqonlar - peasant - peasants. It is natural for solitary nouns to be located in the nucleus and for collective nouns to be located in the periphery.

In general, the relation of the words specific to the noun group in our language to the core-peripheral areas of this group of words in terms of functional-semantic and functional syntactic can be expressed as follows:

Figure. Nuclear-peripheral relationship in nouns 


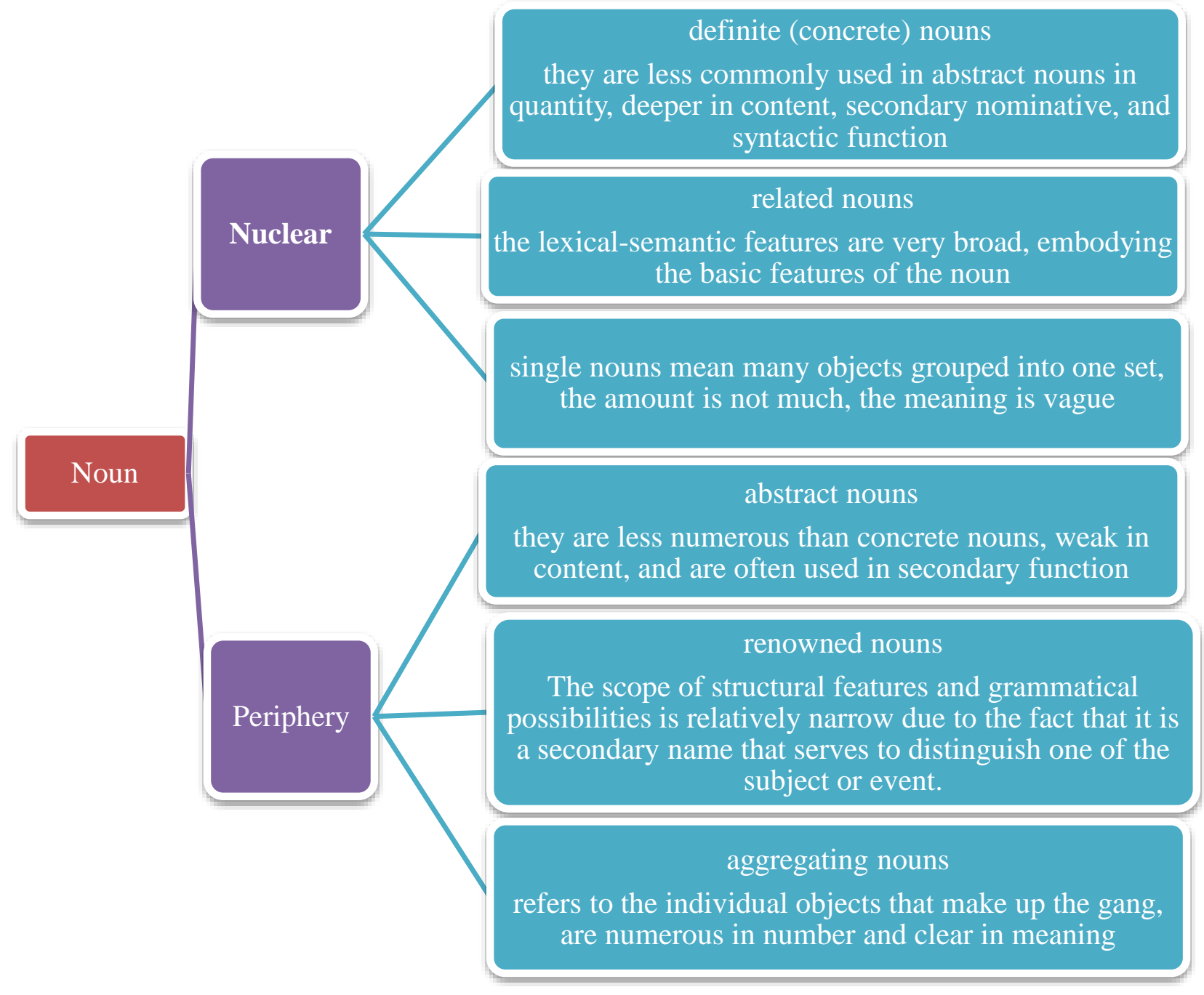

\section{Conclusion}

Thus, although the relation of words belonging to the noun category to the nucleus and periphery can be conditionally expressed as in the diagram, there is a need to describe it in more detail based on the main functional-semantic and functional-syntactic functions of this group.

\section{References}

[1]. Olimova X. V. The structure of famous nouns in the system of different languages (based on materials from English, Uzbek and Russian): Thesis for a master's degree. Samarkand, 2014 -library.ziyonet.uz >book> download (January, 2019)

[2]. Sayfullaeva R.R., Mengliev B.R., Boqieva G.H., Qurbonova M.M., Yunusova Z.Q., 
Abuzalova M.Q. (2006) Modern Uzbek literary language. Study guide. - Tashkent. - p. 208.

[3]. Grammar of the Uzbek language, Volume I. Morphology. - Tashkent. Fan. - 1975. p. 124.

[4]. Hojiev A. (1989) Uzbek word formation. A guide for students of philological faculties of higher educational institutions. - Tashkent. Oqituvchi. - pp. 60-61.

[5]. Ismatullayeva N.R. The verbal lacunas in Chinese and Uzbek languages (on the example of grammatical and somatic lacunas). ACADEMICIA: An International Multidisciplinary Research Journal. Vol 10, Issue 5, May, 2020. - pp. 1696-1700. 